\title{
Article \\ Common Kinetic Mechanism of Abasic Site Recognition by
Structurally Different Apurinic/Apyrimidinic Endonucleases
}

\author{
Alexandra A. Kuznetsova ${ }^{1,+}$, Svetlana I. Senchurova ${ }^{1,2,+}$, Alexander A. Ishchenko ${ }^{3}$, Murat Saparbaev ${ }^{3}$ (D), \\ Olga S. Fedorova ${ }^{1, *(\mathbb{D})}$ and Nikita A. Kuznetsov $1, *(\mathbb{D})$
}

1 Institute of Chemical Biology and Fundamental Medicine, Siberian Branch of Russian Academy of Sciences, 630090 Novosibirsk, Russia; sandra-k@niboch.nsc.ru (A.A.K.); s.senchurova@g.nsu.ru (S.I.S.)

2 Department of Natural Sciences, Novosibirsk State University, 630090 Novosibirsk, Russia

3 Group Mechanisms of DNA Repair and Carcinogenesis, Equipe Labellisée LIGUE 2016, CNRS UMR9019, Gustave Roussy Cancer Campus, Université Paris-Saclay, F-94805 Villejuif, France; Alexander.ISHCHENKO@gustaveroussy.fr (A.A.I.); murat.saparbaev@gustaveroussy.fr (M.S.)

* Correspondence: fedorova@niboch.nsc.ru (O.S.F.); nikita.kuznetsov@niboch.nsc.ru (N.A.K.)

+ These authors contributed equally in this work.

check for updates

Citation: Kuznetsova, A.A.; Senchurova, S.I.; Ishchenko, A.A.; Saparbaev, M.; Fedorova, O.S.; Kuznetsov, N.A. Common Kinetic Mechanism of Abasic Site

Recognition by Structurally Different Apurinic/Apyrimidinic

Endonucleases. Int. J. Mol. Sci. 2021, 22, 8874. https://doi.org/10.3390/ ijms22168874

Academic Editors:

Alexandros Georgakilas and

Andrew Kellett

Received: 16 July 2021

Accepted: 16 August 2021

Published: 18 August 2021

Publisher's Note: MDPI stays neutral with regard to jurisdictional claims in published maps and institutional affiliations.

Copyright: (c) 2021 by the authors. Licensee MDPI, Basel, Switzerland. This article is an open access article distributed under the terms and conditions of the Creative Commons Attribution (CC BY) license (https:/ / creativecommons.org/licenses/by/ $4.0 /)$.

\begin{abstract}
Apurinic/apyrimidinic (AP) endonucleases Nfo (Escherichia coli) and APE1 (human) represent two conserved structural families of enzymes that cleave AP-site-containing DNA in base excision repair. Nfo and APE1 have completely different structures of the DNA-binding site, catalytically active amino acid residues and catalytic metal ions. Nonetheless, both enzymes induce DNA bending, AP-site backbone eversion into the active-site pocket and extrusion of the nucleotide located opposite the damage. All these stages may depend on local stability of the DNA duplex near the lesion. Here, we analysed effects of natural nucleotides located opposite a lesion on catalyticcomplex formation stages and DNA cleavage efficacy. Several model DNA substrates that contain an AP-site analogue [F-site, i.e., (2R,3S)-2-(hydroxymethyl)-3-hydroxytetrahydrofuran] opposite $\mathrm{G}$, $\mathrm{A}, \mathrm{T}$ or $\mathrm{C}$ were used to monitor real-time conformational changes of the tested enzymes during interaction with DNA using changes in the enzymes' intrinsic fluorescence intensity mainly caused by Trp fluorescence. The extrusion of the nucleotide located opposite F-site was recorded via fluorescence intensity changes of two base analogues. The catalytic rate constant slightly depended on the opposite-nucleotide nature. Thus, structurally different AP endonucleases Nfo and APE1 utilise a common strategy of damage recognition controlled by enzyme conformational transitions after initial DNA binding.
\end{abstract}

Keywords: DNA repair; apurinic/apyrimidinic endonuclease; damaged DNA; abasic site; conformational dynamics; stopped-flow enzyme kinetics

\section{Introduction}

Recognition and removal of non-bulky damaged nitrogenous bases from DNA proceed via the base excision repair (BER) pathway initiated by DNA glycosylases [1-3]. By cleaving an apurinic/apyrimidinic (AP)-site and by removing a blocking $3^{\prime}$-end group such as $3^{\prime}$-phospho- $\alpha, \beta$-unsaturated aldehyde or $3^{\prime}$-terminal phosphate, AP endonucleases process the intermediate DNA products generated by DNA glycosylases [4]. AP endonucleases also can recognise some damaged nucleotides containing a modified base, for example, 5,6-dihydrouracil, the $\alpha$-anomer of adenosine or several others [5-11] and initiate DNA glycosylase-independent nucleotide incision repair (NIR) [12-14]. In addition, these enzymes possess endoribonuclease [15-17], 3' -phosphodiesterase, $3^{\prime}$-phosphatase [18] and $3^{\prime} \rightarrow 5^{\prime}$ exonuclease activities [19-21].

AP endonucleases are categorised into two structural families based on their similarity to prokaryotic exonuclease III (Exo III or Xth, Figure 1A) or endonuclease IV (Endo IV or Nfo, Figure 1B) [22-25]. Members of the Xth family have a bilayer $\beta$-sheet flanked by 
$\alpha$-helices and are $\mathrm{Mg}^{2+}$-dependent enzymes. Members of the Nfo family have a structural core in the form of a $\beta$-barrel surrounded by $\alpha$-helices and contain three $\mathrm{Zn}^{2+}$ ions in the active site. According to structural data [24,26], in the Nfo complex with DNA containing an AP-site analogue [F-site, i.e., (2R,3S)-2-(hydroxymethyl)-3-hydroxytetrahydrofuran], the ribose-phosphate backbone of the duplex is bent by $\sim 90^{\circ}$ (Figure 1C, green), and the damaged nucleotide is inserted into the active site of the enzyme. In addition, the nucleotide opposite the lesion is flipped out of the double helix. On the contrary, in an APE1-DNA complex [27], the angle of ribose-phosphate backbone bending is only $~ 35^{\circ}$ (Figure 1C, blue). In this case, the damaged nucleotide is also inserted into the active site, but the nucleotide located opposite the damage retains its stacking with neighbouring bases in the DNA duplex. Despite differences in the structure and metal ion requirements of APE1 and Nfo (Figure 1D), a comparison of their active-site structures surprisingly reveals functional equivalence between $\mathrm{Nfo} \mathrm{Zn}^{2+}$ ions and APE1 catalytic amino acid residues Tyr171, Asp210, Asn212 and His309 [25,28]. Moreover, both enzymes insert some residues (Arg177 and Met207 [APE1] and Arg37, Tyr72 and Leu73 [Nfo], Figure 1A,B) into the void formed in the DNA duplex after damage eversion. These 'void-filling' amino acids can act both as a specific 'wedge' sensing the lesion and as non-specific anchor residues that stabilise the extra-helical position of the damaged nucleotide.

(A)

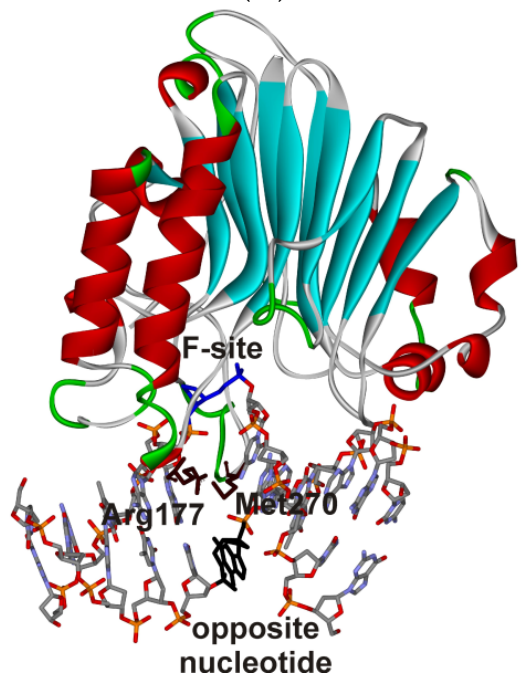

(C)

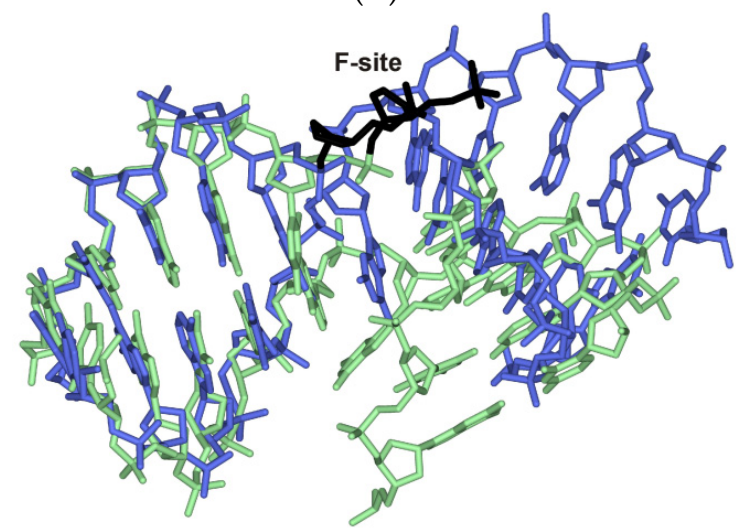

(B)

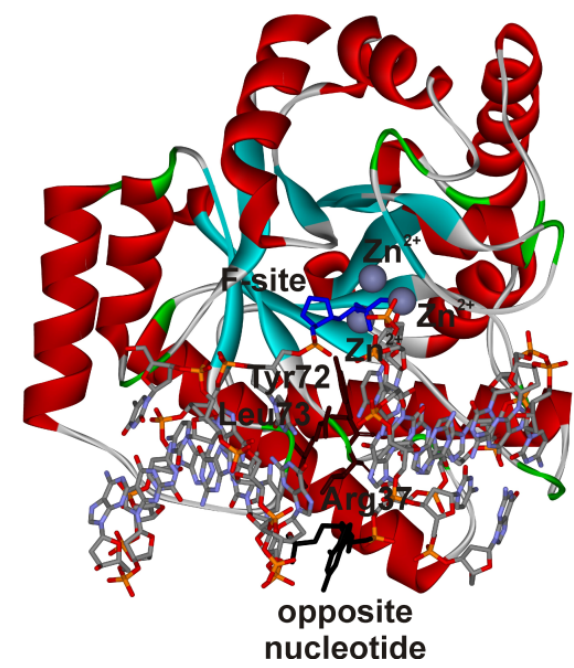

(D)

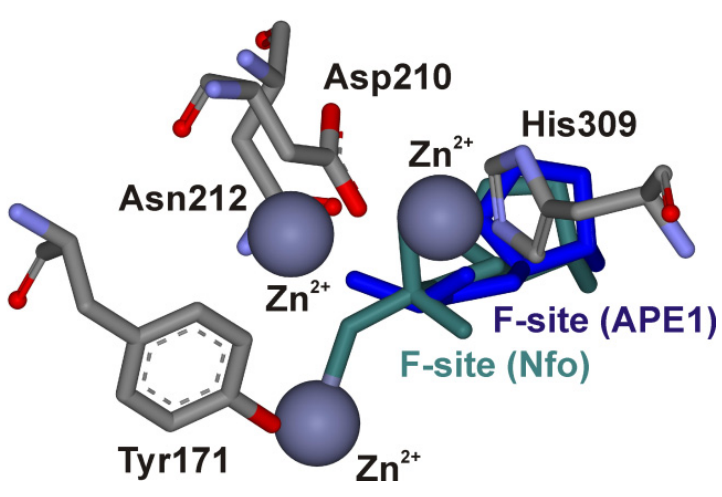

Figure 1. Conformational rearrangements of DNA bound by APE1 (Protein Data Bank ID: 1DE8) (A) or Nfo (Protein Data Bank ID: 1QUM) (B). The damaged nucleotide is blue, the complementary nucleotide is black and 'void-filling' amino acids are highlighted in brown. Structural superposition of DNA bound by APE1 (blue, 1DE8) and Nfo (green, 1QUM) aligned by part of DNA backbone (C). Structural superposition of active sites of APE1 (1DE8) and Nfo (1QUM) aligned by F-site coordinates (D). Residues Tyr171, Asp210, Asn212 and His309 of human APE1 are functionally equivalent to the three $\mathrm{Zn}^{2+}$ ions of Nfo. 
It can be assumed that non-specific contacts between amino acid residues of the DNAbinding site and DNA backbone serve to sculpt DNA structure for bending the double helix, local DNA melting and damaged-nucleotide eversion. The ability of DNA to be bent by the enzyme is related to the flexibility of the double helix. A damaged nucleotide can increase double-helix flexibility or even give rise to stable curvature of DNA, depending on the nature of the nucleobase located opposite the damage. The enzyme-induced distorted state of the DNA helix promotes initial eversion of the damaged nucleotide, and this process may be facilitated by 'wedging' interactions with some of active-site amino acid residues. Of note, such non-specific interactions are mostly independent of the nature of the damaged nucleotide and therefore cannot significantly influence the damage recognition process. In contrast, the nature of the base opposite to the damaged nucleotide may affect the efficacy of the damage eversion owing to an influence on the stability of Watson-Crick hydrogen bonding and on the flexibility of the duplex at the damage site. Therefore, it is important to analyse the effects of natural nucleotides situated opposite the damage on the separate stages of catalytic-complex formation and on the efficacy of DNA cleavage by AP endonucleases APE1 and Nfo. For this purpose, we studied real-time conformational changes of the enzymes during their interaction with damaged DNA containing an abasic site (F-site); these changes were monitored by means of changes in Trp fluorescence intensity. The comparative analysis of the cleavage of the model DNA substrates by AP endonucleases from Nfo and Xth structural families allowed us to elucidate the mechanism of catalytic-complex formation and to reveal the key steps that affected abasic-site recognition.

\section{Results and Discussion}

\subsection{The Rationale}

The mechanism of recognition of abasic site by AP endonucleases includes DNA bending, damaged-nucleotide eversion from the double helix and insertion into the activesite pocket of the enzyme $[24,26,27]$. It could be hypothesise that the efficiency of the DNA bending and abasic site eversion stages can be determined by a few factors: (i) the formation of network contacts with the DNA backbone upstream and downstream of the lesion, (ii) direct 'pushing' or 'pulling' interactions with the damaged nucleotide, (iii) possible steric hindrance between the 2 '-deoxyribose moiety and active-site amino acid residues in the course of the eversion and (iv) the influence of the complementary-nucleotide nature on the ability of the DNA to bend at the damage site.

Structural data permits the assumption that non-specific contacts between DNAbinding site amino acids and the DNA backbone sculpt DNA structure thereby possibly bending the double helix. This enzyme-induced DNA helix distortion promotes the initial flipping of the damaged nucleotide. It is possible that these interactions are mostly independent from the nature of the damaged nucleotide and consequently cannot significantly influence the efficiency of catalytic-complex formation. On the other hand, the opposite base may affect the efficacy of the damaged-nucleotide eversion because of its influence on the energetics of complementary interactions with the lesion and on local flexibility of the duplex near the damaged pair. Moreover, a conformational rearrangement of DNA during the search for and/or specific recognition of the damaged nucleotide can be facilitated by the emergence of direct contacts with the nucleotide located opposite the damage or through inner interactions of the opposite base with neighbouring bases in the double helix. Therefore, the nature of the opposite nucleotide can have an impact on the processes of DNA bending, damage eversion and eventually catalytic-complex formation.

\subsection{Conformational Changes of AP Endonucleases in the Course of F/N-Substrate Cleavage}

Due to the recognition of specific sites in real time accompanied by a conformational adjustment of an enzyme molecule and DNA for optimisation of specific contacts, we performed a pre-steady-state kinetic analysis of conformational changes of the AP endonucleases and model DNA substrates during the enzyme-substrate interaction. Conforma- 
tional changes in the enzyme molecules were monitored via changes in Trp fluorescence intensity. It has been shown [29-31] that despite the rigid protein core of APE1, changes in Trp fluorescence intensity allow us to identify the steps of DNA binding, cleavage and product release. It was likely that one of APE1's seven Trp residues (Figure 2A, Trp280), which is located in the DNA-binding pocket of the enzyme and engages in a hydrogen bond with the 3'-phosphate group of the AP-site, is responsible for the observed changes in fluorescence. Nfo contains four Trp residues distributed in the structure (Figure 2B). It should be noted that one of them, Trp39, binds to the phosphate groups of the nucleotide placed opposite the AP-site, which is everted from the double helix in the catalytic complex. Therefore, the changes in protein fluorescence probably characterise the conformational changes in the Trp39 environment and could be monitored for identifying the extruded nucleotide.

(A)

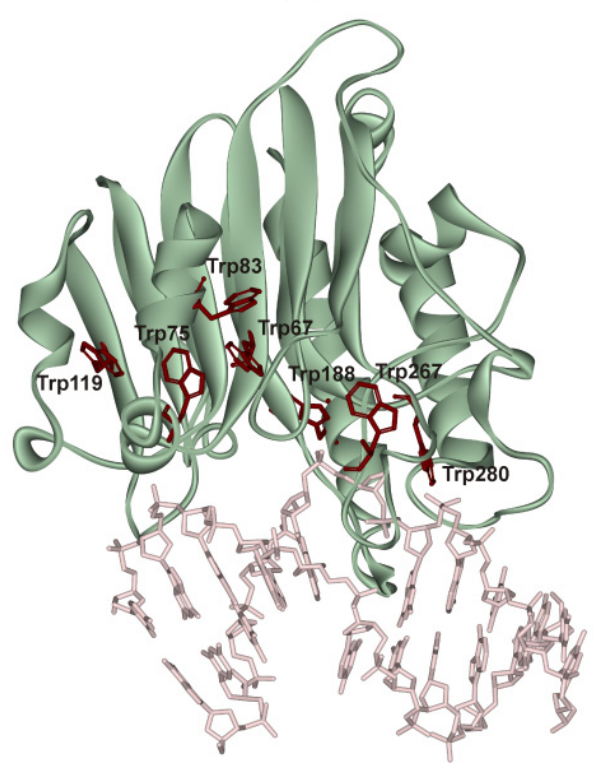

(B)

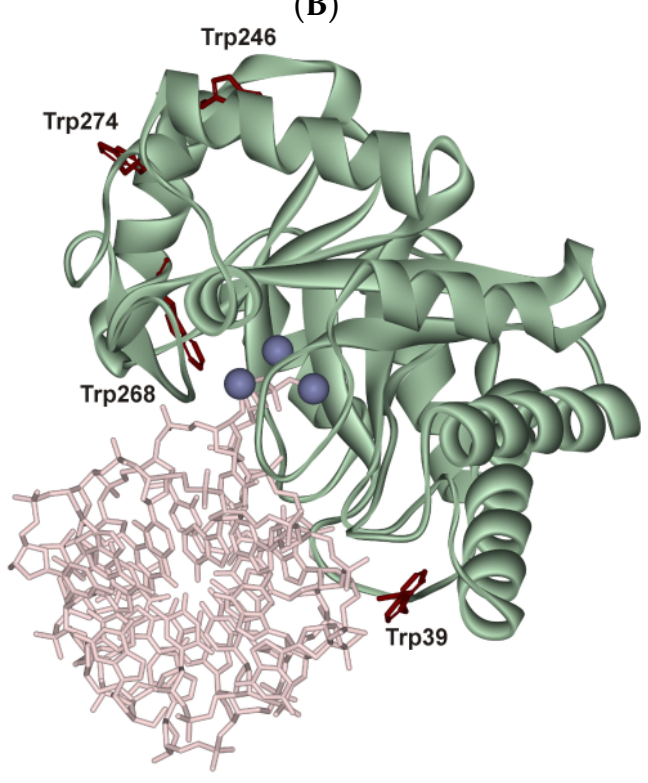

Figure 2. Distribution of Trp residues in spatial structures of human APE1 (A) and Nfo from Escherichia coli $\mathbf{( B )}$.

It has been reported [29] that kinetic traces of APE1's reaction with DNA containing an F-site opposite G (F/G-substrate) comprise the characteristic phases of a decrease and an increase in Trp fluorescence intensity, which can be assigned to DNA-binding steps and catalysis steps, respectively. It was shown that during the recognition of the abasic site in an F/G-substrate, at least two steps of conformational transition occur in the enzyme toward catalytic-complex formation (Scheme 1). In this complex, APE1 excises the phosphodiester bond on the $5^{\prime}$ side of the abasic site. The last step of the kinetic mechanism is the product release. As reported in ref. [32], the formation of the primary enzyme-substrate complex in Scheme 1 is characterised by a positive value of standard entropy change, which was attributed to the desolvation of polar groups in the protein-DNA contact area and to a release of water molecules from DNA grooves, corresponding to transition from highly ordered pseudo-crystalline state to disordered state. This step may include a non-specific interaction between the phosphate groups of the DNA duplex on the $5^{\prime}$ and $3^{\prime}$ sides of the F-site and some amino acid residues of the DNA-binding site, e.g., Arg73, Ala74, Lys78, Trp280, Asn222, Asn226 and Asn229. Moreover, it was assumed that at this moment, Arg177 and Met270 insertion takes place, which is accompanied by the displacement of water molecules in DNA grooves. At the second step of the interaction of APE1 with an F/G-substrate, a specific rearrangement of the primary complex occurs, which includes the F-site eversion into the enzyme active site. 


$$
\mathrm{E}+\mathrm{S} \underset{k_{-1}}{\stackrel{k_{1}}{\rightleftarrows}}(\mathrm{E} \cdot \mathrm{S})_{1} \underset{k_{-2}}{\stackrel{k_{2}}{\rightleftarrows}}(\mathrm{E} \cdot \mathrm{S})_{2} \stackrel{k_{\text {cat }}}{\rightleftarrows} \mathrm{E} \cdot \mathrm{P} \stackrel{K_{\mathrm{P}}}{\rightleftarrows} \mathrm{E}+\mathrm{P}
$$

Scheme 1. The kinetic mechanism underlying the processing of F/N-substrates by the AP endonucleases as revealed by Trp fluorescence intensity detection. E is AP endonuclease; S denotes an $\mathrm{F} / \mathrm{N}$-substrate; $\mathrm{P}$ means the product of the substrate incision reaction; $(\mathrm{E} \bullet \mathrm{S}) 1$ is an initial pre-catalytic enzyme-substrate complex; $(\mathrm{E} \bullet \mathrm{S}) 2$ is a catalytically active enzyme-substrate complex; $\mathrm{E} \bullet \mathrm{P}$ is a complex of the enzyme with the product; $k_{1}, k_{-1}, k_{2}$ and $k_{-2}$ are rate constants of equilibrium steps; and $k_{\text {cat }}$ stands for the rate constant of $5^{\prime}$ phosphodiester bond catalytic cleavage.

To reveal the impact of the opposite nucleotide on the F-site recognition and catalysis, we used the set of F/N pairs where $\mathrm{N}=\mathrm{A}, \mathrm{C}$ or $\mathrm{T}$ (Figure 3). The obtained kinetic traces revealed that the opposite nucleotide significantly affects the kinetic profile of the Trp fluorescence changes during DNA binding. The initial biphasic decrease in Trp fluorescence intensity, revealing the emergence of two pre-excision enzyme-substrate complexes, is distinct for the F/C-substrate. Scheme 1 was employed to fit the observed changes in $\operatorname{Trp}$ fluorescence intensity and enabled us to calculate the rate constants of individual reaction steps (Table 1).

(A)

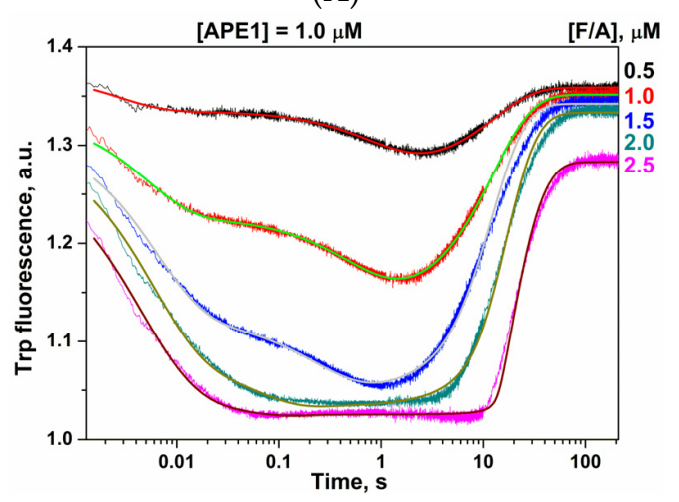

(C)

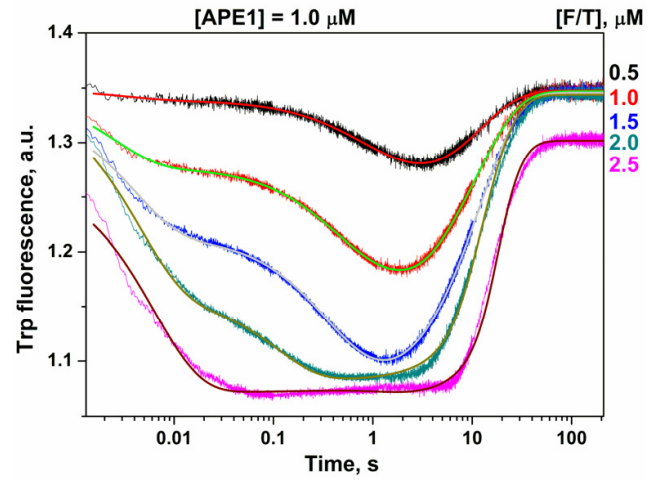

(B)

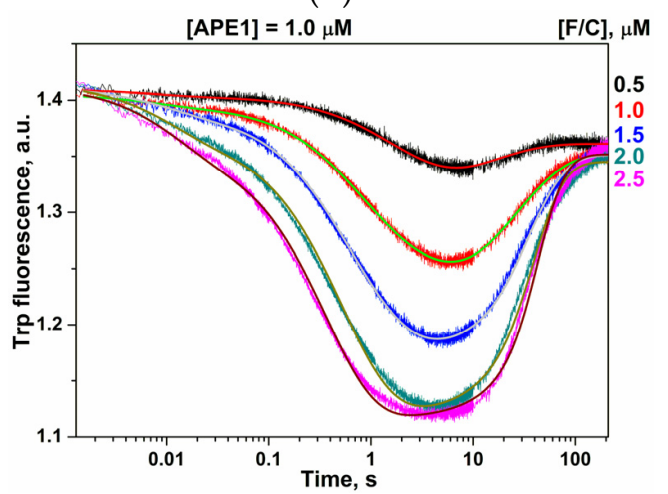

Figure 3. Experimental and theoretical kinetic curves characterising the changes in Trp fluorescence intensity during the interaction of APE1 with an F/N-substrate containing adenosine (A), cytidine (B) or thymidine (C) opposite the F-site. [APE1] = $1.0 \mu \mathrm{M}$. 
Table 1. The rate and equilibrium constants of the interaction of APE1 with an F/N-substrate ${ }^{\text {a }}$.

\begin{tabular}{ccccc}
\hline Constants & F/G ${ }^{\mathbf{b}}$ & F/A & F/C & F/T \\
\hline$k_{1}, \mathrm{M}^{-1} \mathrm{~s}^{-1}$ & $(90 \pm 10) \times 10^{6}$ & $(37 \pm 4) \times 10^{6}$ & $(5.5 \pm 1.2) \times 10^{6}$ & $(58 \pm 7) \times 10^{6}$ \\
$k_{-1}, \mathrm{~s}^{-1}$ & $10.1 \pm 4.3$ & $66 \pm 9$ & $110 \pm 10$ & $120 \pm 10$ \\
$K_{1}, \mathrm{M}^{-1}$ & $(8.9 \pm 4.8) \times 10^{6}$ & $(0.6 \pm 0.1) \times 10^{6}$ & $(0.05 \pm 0.01) \times 10^{6}$ & $(0.5 \pm 0.1) \times 10^{6}$ \\
$k_{2}, \mathrm{~s}^{-1}$ & $43.1 \pm 8.5$ & $3.9 \pm 0.3$ & $11.5 \pm 2.7$ & $10.0 \pm 2.0$ \\
$k_{-2}, \mathrm{~s}^{-1}$ & $7.1 \pm 1.6$ & $0.47 \pm 0.02$ & $0.52 \pm 0.02$ & $0.88 \pm 0.06$ \\
$K_{2}$ & $6.1 \pm 2.6$ & $8.3 \pm 1.0$ & $22 \pm 6$ & $11 \pm 3$ \\
$K_{\text {bind }}, \mathrm{M}^{-1}$ & $(63 \pm 57) \times 10^{6}$ & $(5.6 \pm 1.5) \times 10^{6}$ & $(1.2 \pm 0.5) \times 10^{6}$ & $(6.0 \pm 2.7) \times 10^{6}$ \\
$k_{\text {cat }}, \mathrm{s}^{-1}$ & $0.3 \pm 0.1$ & $0.16 \pm 0.01$ & $0.10 \pm 0.01$ & $0.23 \pm 0.03$ \\
$K_{\mathrm{P}}, \mathrm{M}$ & $(7.2 \pm 0.4) \times 10^{-6}$ & $(1.0 \pm 0.2) \times 10^{-6}$ & $(11 \pm 2) \times 10^{-6}$ & $(32 \pm 5) \times 10^{-6}$ \\
\hline \multicolumn{5}{c}{${ }^{\mathrm{a}} K_{\mathrm{i}}=k_{\mathrm{i}} / k_{-\mathrm{i}}, K_{\text {bind }}=K_{1}+K_{1} \times K_{2}{ }^{\mathrm{b}}{ }^{-6}$ from ref. [29]. }
\end{tabular}

Global fitting showed that binding constant $K_{1}$ of the first DNA-binding step decreases in the order $\mathrm{F} / \mathrm{G}>\mathrm{F} / \mathrm{A} \approx \mathrm{F} / \mathrm{T}>\mathrm{F} / \mathrm{C}$ mostly owing to the destabilisation of the $(\mathrm{E} \bullet \mathrm{S})_{1}$ complex by a significant increase in $k_{-1}$. In contrast, for the $\mathrm{F} / \mathrm{C}$ pair, $k_{1}$ was also 16 -fold lower as compared with the F/G pair. It is noteworthy that the difference in parameters of the second step is not well pronounced and binding constant $K_{2}$ of this step is slightly higher for pyrimidine bases than for purine bases. Moreover, this effect is mostly related to reduced $k_{-2}$, suggesting that the kinked state of the DNA duplex with the everted F-site is stabler in the case of both pyrimidine bases in comparison with the F/G pair. Nonetheless, a comparison of the total binding constants pointed to the same order of substrate-binding strength: $\mathrm{F} / \mathrm{G}>\mathrm{F} / \mathrm{A} \approx \mathrm{F} / \mathrm{T}>\mathrm{F} / \mathrm{C}$. The rate constant of the catalytic step varied in a narrow range from 0.1 to $0.3 \mathrm{~s}^{-1}$, suggesting that the catalytic reaction is independent of the complementary-nucleotide nature. Taken together, this data imply that the complementary nucleotide affects both steps of DNA binding but not the catalytic reaction.

In the course of the Nfo interaction with a duplex containing the F-site, a sequential decrease and increase in Trp fluorescence intensity was observed (Figure 4). Based on the results on APE1, it was likely that the initial decrease in Trp fluorescence characterises the formation of the enzyme-substrate complex. The catalytic stage of the reaction and the dissociation of the enzyme-product complex is accompanied by a subsequent increase in fluorescence intensity of Trp at time points after $10 \mathrm{~s}$. The profile of the decrease phase of fluorescence intensity significantly depends on the nucleotide situated opposite to the F-site. Thus, for the F/G-substrate and F/A-substrate, which contain a purine nucleotide opposite the damage, the decrease phase proceeds quickly, within 10-30 ms (Figure 4A,B). In the case of DNA substrates containing a pyrimidine nucleotide opposite the F-site, after an initial fast decrease of fluorescence intensity, the second slow decrease phase transpired, which was visualised well for the F/C-substrate (Figure 4C). To note, the amplitude of the decreasing phase is $2-3$-fold smaller for the purine orphan base, implying a decrease in the signal-to-noise ratio. 
(A)

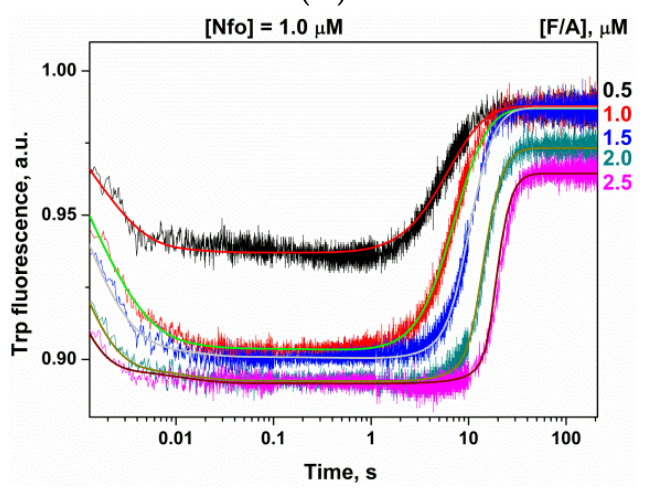

(C)

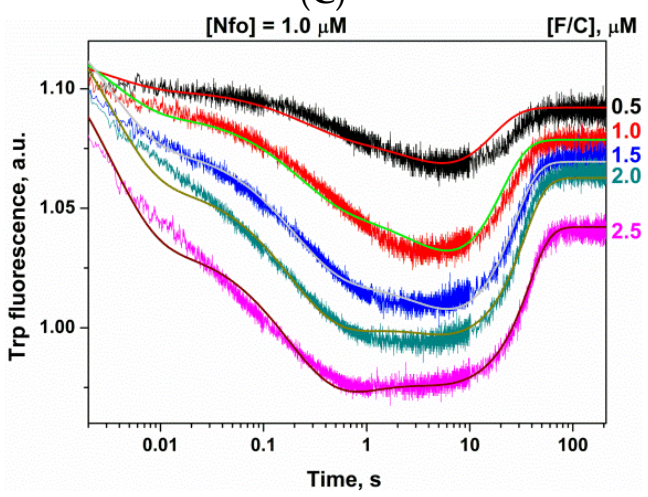

(B)

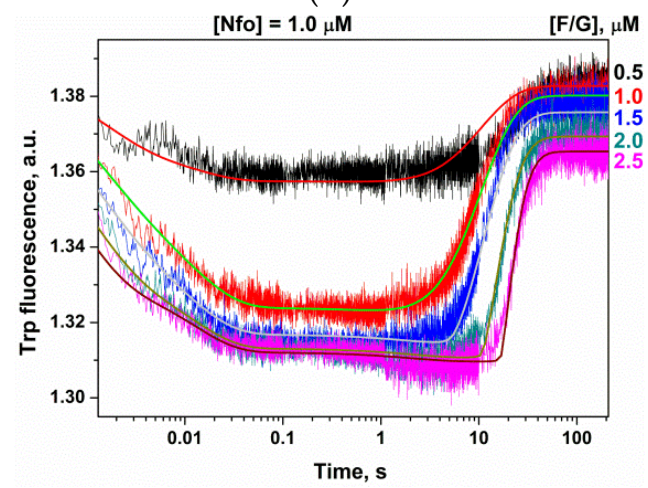

(D)

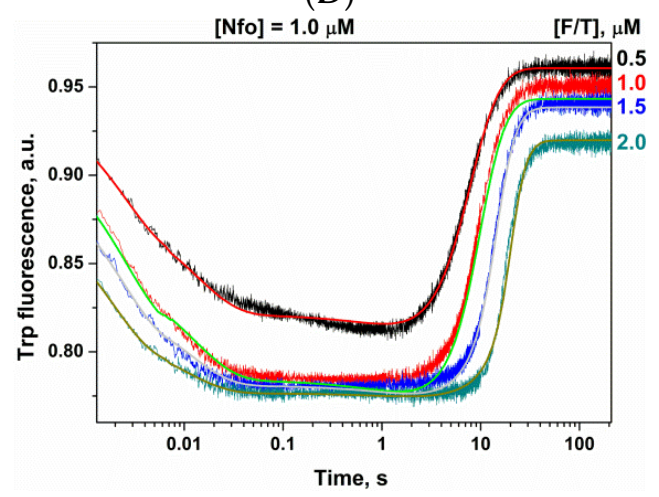

Figure 4. Experimental and theoretical kinetic curves characterising the changes in Trp fluorescence intensity during the interaction of Nfo with an F/N-substrate containing guanosine (A), adenosine (B), cytidine (C) or thymidine (D) opposite the F-site. [Nfo] $=1.0 \mu \mathrm{M}$.

Examination of the kinetic curves suggested that the interaction of Nfo with the F/G-substrate or F/A-substrate is described by a kinetic mechanism involving only one binding step (Scheme 2). On the contrary, for the F/C-substrate and F/T-substrate, the observed kinetic curves were best fitted by Scheme 1, in which the second DNA-binding step corresponds to the slow decrease phase in the kinetic traces. It could be assumed that the smaller signal-to-noise ratio did not permit the resolution of parameters of the second step for purine bases. The rate constants for forward and reverse reactions are given in Table 2. These data revealed that the efficiency of the DNA-binding step, characterised by equilibrium constant $K_{1}$, decreases in the order $F / G>F / A>F / T>F / C$ owing to significant elevation of reverse rate constant $k_{-1}$ from $1.9 \mathrm{~s}^{-1}$ for the $\mathrm{F} / \mathrm{G}$ pair to $270 \mathrm{~s}^{-1}$ for $\mathrm{F} / \mathrm{C}$. A comparison of constants of the second phase monitored in the case of pyrimidine bases uncovered a similar equilibrium constant $K_{2}$ for both the F/T-substrate and F/Csubstrate. Analysis of rate constants suggests that the second step is very fast $\left(k_{2}=101 \mathrm{~s}^{-1}\right)$ for the F/T-substrate. When the F/C-substrate was used, the rate constant of the second step was lower by a factor of $\sim 10\left(k_{2}=9.1 \mathrm{~s}^{-1}\right)$, thereby leading to an extension and shift of the Trp fluorescence intensity decreasing phase up to $1 \mathrm{~s}$. It is likely that for purine bases, the molecular events during this step proceed even faster and therefore cannot be detected as separate steps in the kinetic mechanism. The total binding constants decrease in the order F/G > F/A > F/T > F/C too. The catalytic rate constant also varied in a narrow range from 0.10 to $0.27 \mathrm{~s}^{-1}$, just as the constant for APE1, thereby implying independence of the hydrolysis reaction on the opposite-nucleotide nature. 


$$
\mathrm{E}+\mathrm{S} \underset{k_{-1}}{\stackrel{k_{1}}{\rightleftarrows}} \mathrm{E} \cdot \mathrm{S} \stackrel{k_{\text {cat }}}{\longrightarrow} \mathrm{E} \cdot \mathrm{P} \stackrel{K_{\mathrm{P}}}{\rightleftarrows} \mathrm{E}+\mathrm{P}
$$

Scheme 2. The kinetic mechanism behind the processing of the F/G-substrate or F/A-substrate by Nfo. E is an AP endonuclease, $\mathrm{S}$ denotes an F/N-substrate, $\mathrm{P}$ represents the product of the substrate

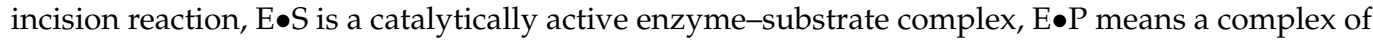
the enzyme with the product, $k_{1}$ and $k_{-1}$ are rate constants of equilibrium steps and $k_{\text {cat }}$ stands for the rate constant of catalytic cleavage of the $5^{\prime}$ phosphodiester bond.

Table 2. The rate and equilibrium constants of the interaction of Nfo with an F/N-substrate ${ }^{\text {a }}$.

\begin{tabular}{ccccc}
\hline Constants & F/G & F/A & F/C & F/T \\
\hline$k_{1}, \mathrm{M}^{-1} \mathrm{~s}^{-1}$ & $(151 \pm 2) \times 10^{6}$ & $(360 \pm 10) \times 10^{6}$ & $(150 \pm 10) \times 10^{6}$ & $(360 \pm 10) \times 10^{6}$ \\
$k_{-1}, \mathrm{~s}^{-1}$ & $1.9 \pm 0.2$ & $30 \pm 1$ & $270 \pm 10$ & $235 \pm 10$ \\
$K_{1}, \mathrm{M}^{-1}$ & $(80 \pm 9) \times 10^{6}$ & $(12 \pm 1) \times 10^{6}$ & $(0.55 \pm 0.06) \times 10^{6}$ & $(1.5 \pm 0.1) \times 10^{6}$ \\
$k_{2}, \mathrm{~s}^{-1}$ & - & - & $9.1 \pm 0.2$ & $101 \pm 2$ \\
$k_{-2}, \mathrm{~s}^{-1}$ & - & - & $4.4 \pm 0.1$ & $28 \pm 1$ \\
$K_{2}$ & - & - & $2.1 \pm 0.1$ & $3.6 \pm 0.2$ \\
$K_{\text {bind }}, \mathrm{M}^{-1}$ & $(80 \pm 9) \times 10^{6}$ & $(12 \pm 1) \times 10^{6}$ & $(1.7 \pm 0.2) \times 10^{6}$ & $(6.9 \pm 0.8) \times 10^{6}$ \\
$k_{\text {cat }}, \mathrm{s}^{-1}$ & $0.10 \pm 0.01$ & $0.18 \pm 0.02$ & $0.27 \pm 0.01$ & $0.23 \pm 0.01$ \\
$K_{\mathrm{P}}, \mathrm{M}$ & $(11 \pm 1) \times 10^{-6}$ & $(5.8 \pm 0.4) \times 10^{-6}$ & $(6.9 \pm 0.4) \times 10^{-6}$ & $(2.7 \pm 0.1) \times 10^{-6}$ \\
\hline
\end{tabular}

$$
{ }^{\mathrm{a}} K_{\mathrm{i}}=k_{\mathrm{i}} / k_{-\mathrm{i}}, K_{\mathrm{bind}}=K_{1}+K_{1} \times K_{2} \text {. }
$$

\subsection{Direct PAGE Analysis of F/N-Substrate Cleavage}

The rates of the formation of the cleaved DNA product were directly measured for APE1 and Nfo by PAGE with ${ }^{32}$ P-labelled F/N-substrates (Figure 5). Scheme 3 was utilised to describe the resultant kinetic curves. The equilibrium constant was borrowed from the stopped-flow data (Tables 1 and 2 for APE1 and Nfo, respectively) and was designated as the total binding constant, $K_{\text {bind }}$. The constant of the irreversible step, $k_{\mathrm{cat}}{ }^{\mathrm{PAGE}}$, was estimated by non-linear fitting. The $k_{\mathrm{cat}}{ }^{\mathrm{PAGE}}$ values were slightly dependent on the nature of the nucleotide located opposite the F-site and were close to the $k_{\text {cat }}$ determined in the stopped-flow experiments (Figure 6).

(A)

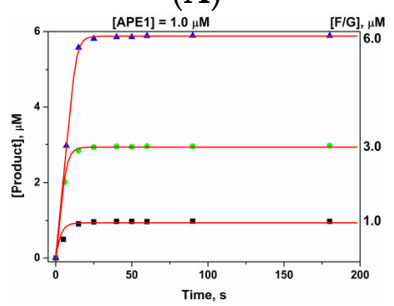

(E)

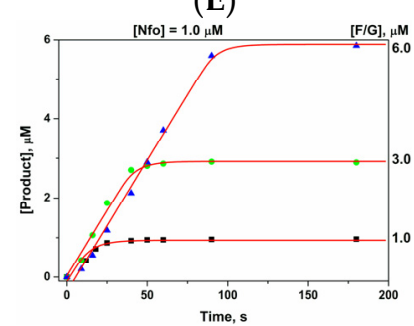

(B)

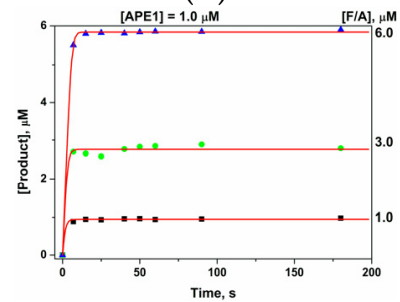

(F)

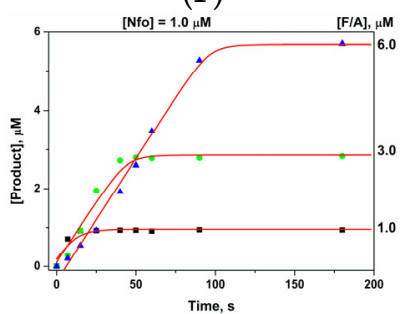

(C)

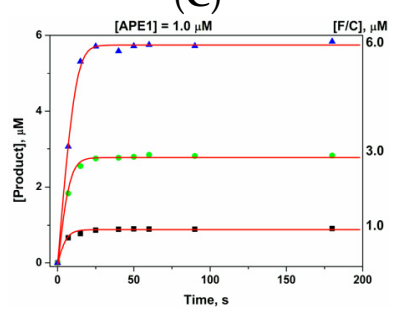

(G)

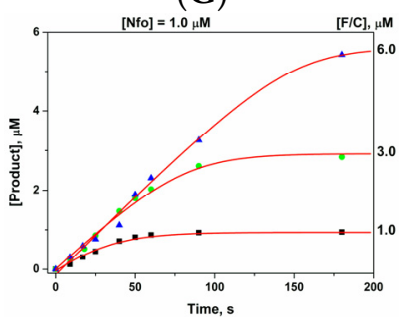

(D)

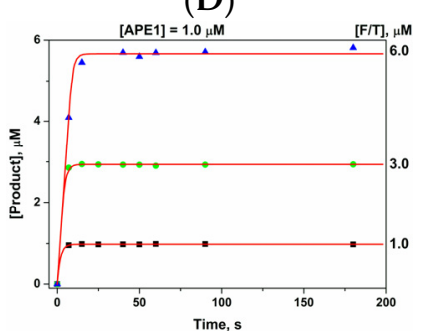

$(\mathbf{H})$

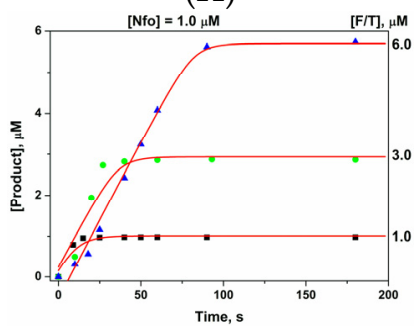

Figure 5. The time course of the accumulation of products during interactions of APE1 (A-D) or Nfo (E-H) with the F/G$(\mathbf{A}, \mathbf{E}), \mathrm{F} / \mathrm{A}-(\mathbf{B}, \mathbf{F}), \mathrm{F} / \mathrm{C}-(\mathbf{C}, \mathbf{G})$ or F/T-substrate $(\mathbf{D}, \mathbf{H})$. Concentrations of the AP endonucleases and DNA are shown in the panels. 


$$
\mathrm{E}+\mathrm{S} \stackrel{K_{\text {bind }}}{\rightleftarrows} \mathrm{E} \cdot \mathrm{S} \stackrel{k_{\text {cat }}^{\text {PAGE }}}{\longrightarrow} \mathrm{E}+\mathrm{P}
$$

Scheme 3. The kinetic mechanism of DNA product accumulation in PAGE analysis. E is AP endonuclease, $\mathrm{S}$ denotes the $\mathrm{F} / \mathrm{N}$-substrate, $\mathrm{P}$ represents the product of the substrate incision reaction, E•S is the catalytically active enzyme-substrate complex, $K_{\text {bind }}$ means the equilibrium constant of binding step and $k_{\text {cat }}{ }^{\text {PAGE }}$ stands for the rate constant of catalytic cleavage of the $5^{\prime}$ phosphodiester bond.

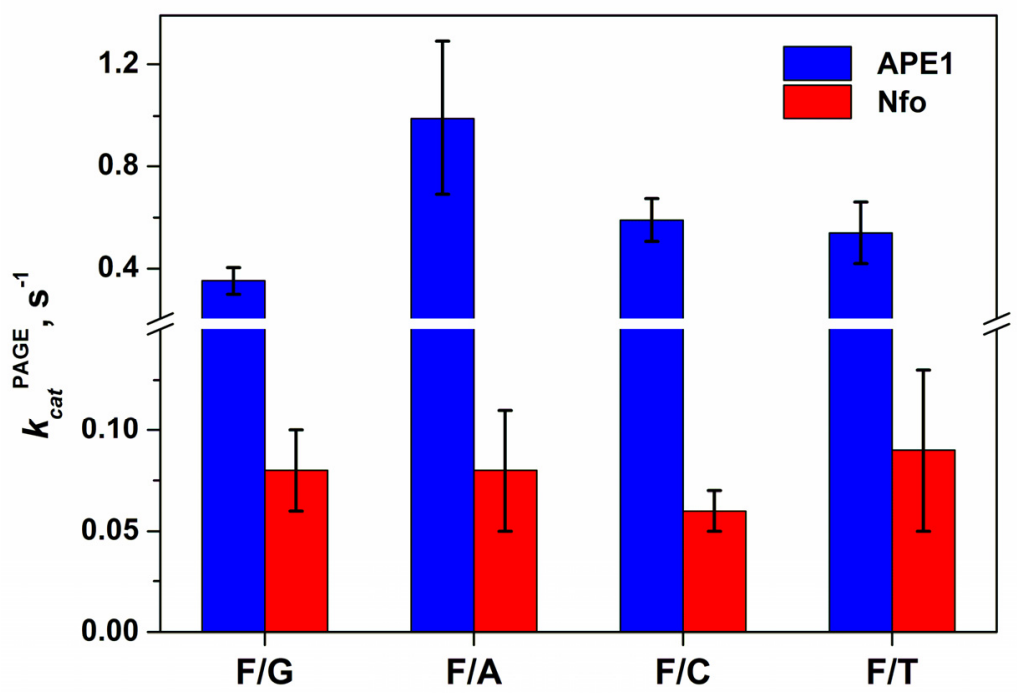

Figure 6. The efficacy of F/N-substrate cleavage by AP endonucleases APE1 and Nfo as evidenced by PAGE analysis.

\subsection{Fluorescent Detection of Opposite-Nucleotide Extrusion in the Course of Catalytic-Complex Formation}

To register the process of opposite-base extrusion from DNA, we used fluorescent analogues of DNA bases, namely, bicyclic cytosine analogue, pyrrolocytosine (3-[ $\beta$-D-2ribofuranosyl]-6-methylpyrrolo [2,3-d]pyrimidin-2(3H)-one, $\mathrm{C}^{\mathrm{py}}$ ) [33-35] and a tricyclic cytosine analogue, 1,3-diaza-2-oxophenoxazine $\left(\mathrm{tC}^{\mathrm{O}}\right)[36,37]$, which are sensitive to changes of a microenvironment. Typically, the fluorescence of most analogues is quenched by neighbouring nitrogenous bases, and quenching efficiency depends on both the nature of the base and spatial structure of the nucleic acid. Nevertheless, as reported in our previous works, the changes in fluorescence intensity of these bases during protein-DNA interactions are much more complicated than simple quenching by neighbouring bases $[38,39]$. Therefore, here we performed only a qualitative analysis of fluorescence changes during the interaction of APE1 or Nfo with an F/X-substrate, where $\mathrm{X}$ was either $\mathrm{C}^{\mathrm{py}}$ or $\mathrm{tC}^{\mathrm{O}}$ (Figure 7). Of note, during initial $0.1 \mathrm{~s}$, fluorescence intensity of $\mathrm{tC}^{\mathrm{O}}$ declined for Nfo but did not change for APE1. In contrast, $\mathrm{C}^{\mathrm{py}}$ fluorescence was quite stable in the case of Nfo but significantly dropped for APE1 in the interval from 0.1 to $1.0 \mathrm{~s}$. A comparison of these changes with conformational alterations of the enzymes indicated that the decrease of $C^{p y}$ fluorescence intensity by time points $1 \mathrm{~s}$ for APE1 or the increase in the $\mathrm{tC}^{\mathrm{O}}$ signal by time point $0.1 \mathrm{~s}$ for Nfo are in good agreement with the second decrease phase of the Trp signal detected for APE1 (Figure 3) and Nfo interacting with the F/C-substrate or F/T-substrate (Figure 4C,D). These findings mean that the opposite-base extrusion proceeds during the second binding step as enzyme-induced conformational transition of the DNA substrate. As evidenced by Trp fluorescence and the conformational alterations of both enzymes, the opposite base influences both substrate-binding steps; therefore, it can be concluded that the nature of the F/N pair determines DNA's local specific properties, which affect the enzymes in the initial complex. 
(A)

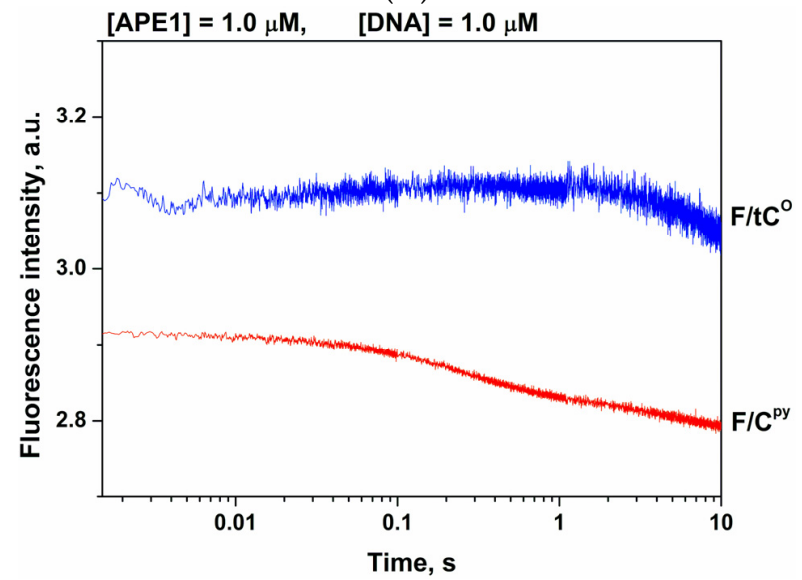

(B)

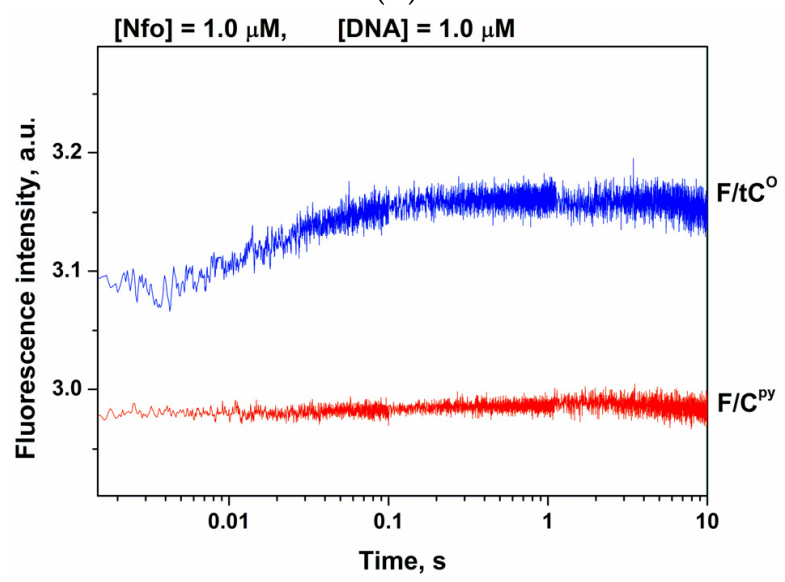

Figure 7. Kinetic curves characterising the opposite-nucleotide extrusion by APE1 (A) or Nfo (B).

\section{Materials and Methods}

\subsection{Protein Expression and Purification}

To purify Nfo expressed as a recombinant protein, $1 \mathrm{~L}$ of culture (in Luria-Bertani [LB] broth) of Escherichia coli strain BL21(DE3) (Invitrogen, France) carrying the pET11aNfo construct was grown with $50 \mu \mathrm{g} / \mathrm{mL}$ ampicillin at $37^{\circ} \mathrm{C}$ until absorbance at $600 \mathrm{~nm}$ $\left(\mathrm{A}_{600}\right)$ reached $0.6-0.7$; Nfo expression was induced overnight with $0.2 \mathrm{mM}$ isopropyl- $\beta$-dthiogalactopyranoside. The method for the isolation of wild-type Nfo has been described previously [5]. Human APE1 was purified as described earlier [32,40]. The protein concentration was measured by the Bradford method [41]; the stock solution was stored at $-20{ }^{\circ} \mathrm{C}$ in $50 \%$ glycerol.

\subsection{Oligodeoxynucleotides (ODNs)}

Sequences of the ODNs used in this work are listed in Table 3. The ODNs were synthesised by established phosphoramidite methods on an ASM-700 synthesiser (BIOSSET Ltd., Novosibirsk, Russia) from phosphoramidites purchased from Glen Research (Sterling, VA, USA). Synthetic oligonucleotides were unloaded from solid support according to the manufacturer's protocols. Deprotected oligonucleotides were purified by high-performance liquid chromatography. Concentrations of oligonucleotides were calculated from their $\mathrm{A}_{260}$. ODN duplexes were prepared by annealing modified and complementary strands at a 1:1 molar ratio.

Table 3. DNA sequences and structure of the lesion introduced into the DNA duplexes.

\begin{tabular}{cc}
\hline Shorthand & Sequences of DNA Duplexes \\
\hline F/N-substrate & $5^{\prime}$-CTCTCFCCTTCC-3' \\
$\mathrm{N}=\mathrm{G}, \mathrm{A}, \mathrm{T}, \mathrm{C}$ & 3'-GAGAGNGGAAGG-5' $^{\prime}$
\end{tabular}

$\mathrm{F}$ is (2R,3S)-2-(hydroxymethyl)-3-hydroxytetrahydrofuran (an AP-site analogue).

\subsection{Enzyme Assays by Polyacrylamide Gel Electrophoresis (PAGE)}

The enzyme assays involving all the DNA substrates were carried out at $25{ }^{\circ} \mathrm{C}$ in reaction buffer [50 mM Tris- $\mathrm{HCl} \mathrm{pH} 7.5,100 \mathrm{mM} \mathrm{KCl}, 1.0 \mathrm{mM}$ EDTA, $1.0 \mathrm{mM}$ DDT and $7 \%$ of glycerol $(v / v)]$. In the case of APE1, reaction buffer was supplemented with $5.0 \mathrm{mM} \mathrm{MgCl}$. Substrate oligonucleotides were $5^{\prime}-32 \mathrm{P}$-labelled using T4 polynucleotide kinase and $\left[\gamma^{-32} \mathrm{P}\right] \mathrm{ATP}$. Enzyme concentration was $1.0 \mu \mathrm{M}$, and the concentration of a substrate was varied from 1.0 to $6.0 \mu \mathrm{M}$. Aliquots of the reaction mixture were withdrawn, immediately quenched with formamide containing $25 \mathrm{mM}$ EDTA and $0.1 \%$ xylene cyanol in a volume equal to the aliquot volume, were incubated at $95{ }^{\circ} \mathrm{C}$ for $3 \mathrm{~min}$ and then were loaded on a $20 \%$ polyacrylamide gel containing $7 \mathrm{M}$ urea. Agfa CP-BU X-ray film 
(Agfa-Geavert, Mortsel, Belgium) was exposed to the gels. The formation of the product was quantified by scanning densitometry in the Gel-Pro Analyzer software, v.4.0 (Media Cybernetics, Rockville, MD, USA). Kinetic parameters were calculated by numerical fitting using DynaFit software (BioKin, Pullman, WA, USA) [42] as described before [43].

\subsection{Stopped-Flow Fluorescence Measurements}

The stopped-flow measurements with fluorescence detection were carried out mostly as described elsewhere $[44,45]$ on an SX.18MV stopped-flow spectrometer (Applied Photophysics Ltd., Leatherhead, UK) equipped with a $150 \mathrm{~W}$ Xe arc lamp and an optical cell with 2 -mm path length. The dead time of the instrument is $1.4 \mathrm{~ms}$. The fluorescence of Trp was excited at $\lambda_{\mathrm{ex}}=290 \mathrm{~nm}$ and monitored at $\lambda_{\mathrm{em}}>320 \mathrm{~nm}$ as transmitted by filter WG-320 (Schott, Mainz, Germany). All the experiments were conducted in a buffer consisting of $50 \mathrm{mM}$ Tris-HCl pH 7.5, $100 \mathrm{mM} \mathrm{KCl}, 1.0 \mathrm{mM}$ EDTA, $1.0 \mathrm{mM}$ DTT and 7\% of glycerol $(v / v)$. In the case of APE1, reaction buffer was supplemented with $5.0 \mathrm{mM} \mathrm{MgCl}_{2}$.

An enzyme was placed in one of the instrument's syringes and rapidly mixed in the reaction chamber with a DNA substrate from another syringe. The concentrations of the DNA substrate and enzyme are indicated in the figure legends. The reported concentrations of the reactants are those in the reaction chamber after the mixing. Typically, each trace shown in the figures is the average of four or more fluorescence traces recorded in individual experiments. In the figures, for better presentation, the curves were manually moved apart. This procedure does not affect the results of fitting because the background fluorescence is fitted separately for each curve. Kinetic curves were analysed in the DynaFit software (BioKin, Pullman, WA, USA) [42] as described elsewhere [36,37,46,47].

\section{Conclusions}

In spite of extensive studies on AP endonucleases, the molecular basis for their broad substrate specificity and the mechanism of discrimination between modified bases and/or nucleotides as well as undamaged DNA bases are not yet clear. The substrate specificity in relation to a specific site may have something to do with various distortions of local DNA structure around the abasic site, which influence the efficiency of transition to the catalytically active conformation. Another basis for substrate recognition may be related to differences in the efficiency of abasic-site eversion, which is dependent on the nature of the opposite base and/or on local stability of the damaged region in DNA. According to the multiple studies $[48,49]$ on interactions of DNA repair enzymes with their specific site, the common mechanism of damage recognition that ensures high substrate specificity can be subdivided into several steps: the bending of damaged DNA by the enzyme, eversion of the damaged nucleotide from the double helix and verification of the damaged base in the active site of the enzyme through the formation of specific contacts.

Even though it is widely believed that the C-terminal catalytic domain of AP endonucleases accounts for the specific binding to DNA, their N-terminal domains, which substantially vary in size and are not visible in crystal structure, may influence DNA-binding abilities [50-52]. Indeed, analysis of APE1 variants with a truncated N-terminal part has revealed that this lysine-rich region may act by stabilising nonspecific association with a nucleic acid through electrostatic interactions [53,54]. A loss of the $\mathrm{N}$-terminal domain influences the stability of both enzyme-substrate and enzyme-product complexes $[55,56]$ but does not affect the rates of initial complex formation or catalysis [31] in the case of the incision of abasic-site-containing DNA. By contrast, this domain affects both the rate of the formation and stability of the initial complex for NIR and $3^{\prime} \rightarrow 5^{\prime}$ exonuclease activities $[10,14,31]$. Multiple studies also indicate that the N-terminal domain may functionally interact with various proteins involved in DNA repair [57-60], transcription [61-63] and RNA metabolism [54,64-66]. Nevertheless, AP endonuclease Xth from E. coli (which belongs to the same structural family as APE1 does), when lacking an N-terminal region, also shows various activities toward different orphan nucleotides [67]. Summarising the literature data, it can be concluded that the $\mathrm{N}$-terminal domain may be required for the 
preliminary low-affinity binding process during the search for a suitable lesion in DNA or a cleavage site in RNA and during protein-protein interactions. Therefore, in the present study, we compare properties of AP endonucleases by taking into account differences in the main catalytic domain, which is responsible for the specific DNA binding.

In the present work, we analysed the effects of natural nucleotides situated opposite a lesion on the stages of catalytic-complex formation and on the efficacy of DNA cleavage by AP endonucleases: human APE1 and Nfo from E. coli, which have completely different protein architectures and structures of the DNA-binding site. A set of model DNA substrates containing the F-site opposite $G, A$, T or C was used to monitor real-time conformational alterations of the analysed enzymes during their interaction with DNA by means of changes in Trp fluorescence intensity. Our stopped-flow Trp data suggest that catalytic-complex formation in most cases proceeds through a two-step kinetic mechanism of binding.

These findings permit the conclusion that kinetic parameters of the binding steps resulting in a catalytically competent enzyme-substrate complex are significantly different among the tested $\mathrm{F} / \mathrm{N}$-substrates, indicating the importance of the opposite-base nature. Initial-DNA-binding constants and total binding constants typically decrease in the order $\mathrm{F} / \mathrm{G}>\mathrm{F} / \mathrm{A} \geq \mathrm{F} / \mathrm{T}>\mathrm{F} / \mathrm{C}$.

The absence of direct contacts of the enzyme with the base located opposite to the damage suggests that the conformational DNA rearrangements induced by the enzymes are dependent on the internal interactions of the nucleotide located opposite the lesion with the neighbouring bases in the double DNA helix. It was demonstrated that catalytic rate constants are mostly independent from the nature of the opposite base. Therefore, in the course of enzyme conformational transitions, the efficacy of damaged-DNA cleavage with respect to various nucleotides in the complementary strand is controlled mostly during initial-complex formation. On the contrary, in the Nfo interaction with an F/N-substrate, the extrusion of purine bases at the second step of the interaction proceeds much faster than that of pyrimidine bases thereby eliminating this step from the kinetic scheme.

Taken together, our results for the first time show that structurally different AP endonucleases Nfo and APE1 utilise a common strategy of damage recognition, which involves the formation of an initial enzyme-substrate complex and its subsequent transformation to the catalytic state. It could be concluded that local structural properties of DNA near damaged nucleotide is crucial for efficient initial lesion-sensing and subsequent formation of the catalytic complex independently on the structure of the enzyme active site.

Author Contributions: Conceptualisation, N.A.K.; methodology, N.A.K. and O.S.F.; software, N.A.K. and O.S.F.; validation, A.A.K., S.I.S., N.A.K. and O.S.F.; formal analysis, A.A.K. and S.I.S.; investigation, A.A.K. and S.I.S.; resources, A.A.I., M.S., N.A.K. and O.S.F.; data curation, A.A.K., N.A.K. and O.S.F.; writing —original draft preparation, N.A.K. and O.S.F.; writing—review and editing, N.A.K., A.A.I., M.S. and O.S.F.; visualisation, N.A.K.; supervision, N.A.K.; project administration, N.A.K. and O.S.F.; funding acquisition, A.A.K., N.A.K., A.A.I., M.S. and O.S.F. All authors have read and agreed to the published version of the manuscript.

Funding: This work was supported partially by a Russian-Government-funded project (No. AAAAA17-117020210022-4), by Electricité de France (RB 2021-05, to M.S.) and by French National Research Agency (ANR-18-CE44-0008, to A.A.I.). The part of this work involving Trp detection combined with stopped-flow kinetics was specifically funded by Russian Science Foundation grant No. 19-74-10034.

Institutional Review Board Statement: Not applicable.

Informed Consent Statement: Not applicable.

Data Availability Statement: Data is contained within the article.

Conflicts of Interest: The authors declare that the research was conducted in the absence of any commercial or financial relationships that could be construed as a potential conflict of interest. 


\section{References}

1. Dodson, M.L.; Michaels, M.L.; Lloyd, R.S. Unified catalytic mechanism for DNA glycosylases. J. Biol. Chem. 1994, 269, 32709-32712. [CrossRef]

2. Dodson, M.L.; Lloyd, R.S. Mechanistic comparison among base exision repair glycosylases. Free Radic. Biol. Med. 2002, 32, 678-682. [CrossRef]

3. Gros, L.; Saparbaev, M.K.; Laval, J. Enzymology of the repair of free radicals-induced DNA damage. Oncogene 2002, 21, 8905-8925. [CrossRef]

4. Jacobs, A.L.; Schar, P. DNA glycosylases: In DNA repair and beyond. Chromosoma 2012, 121, 1-20. [CrossRef]

5. Golan, G.; Ishchenko, A.A.; Khassenov, B.; Shoham, G.; Saparbaev, M.K. Coupling of the nucleotide incision and $3^{\prime} \rightarrow 5^{\prime}$ exonuclease activities in Escherichia coli endonuclease IV: Structural and genetic evidences. Mutat. Res. 2010, 685, 70-79. [CrossRef]

6. Prorok, P.; Saint-Pierre, C.; Gasparutto, D.; Fedorova, O.S.; Ishchenko, A.A.; Leh, H.; Buckle, M.; Tudek, B.; Saparbaev, M. Highly mutagenic exocyclic DNA adducts are substrates for the human nucleotide incision repair pathway. PLoS ONE 2012, 7, e51776. [CrossRef]

7. Christov, P.P.; Banerjee, S.; Stone, M.P.; Rizzo, C.J. Selective Incision of the alpha-N-Methyl-Formamidopyrimidine Anomer by Escherichia coli Endonuclease IV. J. Nucleic Acids 2010, 2010, 850234. [CrossRef]

8. Vrouwe, M.G.; Pines, A.; Overmeer, R.M.; Hanada, K.; Mullenders, L.H. UV-induced photolesions elicit ATR-kinase-dependent signaling in non-cycling cells through nucleotide excision repair-dependent and -independent pathways. J. Cell Sci. 2011, 124, 435-446. [CrossRef]

9. Guliaev, A.B.; Hang, B.; Singer, B. Structural insights by molecular dynamics simulations into specificity of the major human AP endonuclease toward the benzene-derived DNA adduct, pBQ-C. Nucleic Acids Res. 2004, 32, 2844-2852. [CrossRef]

10. Daviet, S.; Couve-Privat, S.; Gros, L.; Shinozuka, K.; Ide, H.; Saparbaev, M.; Ishchenko, A.A. Major oxidative products of cytosine are substrates for the nucleotide incision repair pathway. DNA Repair 2007, 6, 8-18. [CrossRef]

11. Prorok, P.; Alili, D.; Saint-Pierre, C.; Gasparutto, D.; Zharkov, D.O.; Ishchenko, A.A.; Tudek, B.; Saparbaev, M.K. Uracil in duplex DNA is a substrate for the nucleotide incision repair pathway in human cells. Proc. Natl. Acad. Sci. USA 2013, 110, E3695-E3703. [CrossRef] [PubMed]

12. Ischenko, A.A.; Saparbaev, M.K. Alternative nucleotide incision repair pathway for oxidative DNA damage. Nature 2002, 415, 183-187. [CrossRef]

13. Ishchenko, A.A.; Sanz, G.; Privezentzev, C.V.; Maksimenko, A.V.; Saparbaev, M. Characterisation of new substrate specificities of Escherichia coli and Saccharomyces cerevisiae AP endonucleases. Nucleic Acids Res. 2003, 31, 6344-6353. [CrossRef]

14. Gros, L.; Ishchenko, A.A.; Ide, H.; Elder, R.H.; Saparbaev, M.K. The major human AP endonuclease (Ape1) is involved in the nucleotide incision repair pathway. Nucleic Acids Res. 2004, 32, 73-81. [CrossRef] [PubMed]

15. Barzilay, G.; Walker, L.J.; Robson, C.N.; Hickson, I.D. Site-directed mutagenesis of the human DNA repair enzyme HAP1: Identification of residues important for AP endonuclease and RNase H activity. Nucleic Acids Res. 1995, 23, 1544-1550. [CrossRef]

16. Berquist, B.R.; McNeill, D.R.; Wilson III, D.M. Characterization of abasic endonuclease activity of human Ape1 on alternative substrates, as well as effects of ATP and sequence context on AP site incision. J. Mol. Biol 2008, 379, 17-27. [CrossRef] [PubMed]

17. Barnes, T.; Kim, W.C.; Mantha, A.K.; Kim, S.E.; Izumi, T.; Mitra, S.; Lee, C.H. Identification of Apurinic/apyrimidinic endonuclease 1 (APE1) as the endoribonuclease that cleaves c-myc mRNA. Nucleic Acids Res. 2009, 37, 3946-3958. [CrossRef] [PubMed]

18. Chen, D.S.; Herman, T.; Demple, B. Two distinct human DNA diesterases that hydrolyze 3'-blocking deoxyribose fragments from oxidized DNA. Nucleic Acids Res. 1991, 19, 5907-5914. [CrossRef]

19. Chou, K.M.; Cheng, Y.C. An exonucleolytic activity of human apurinic/apyrimidinic endonuclease on 3 ' mispaired DNA. Nature 2002, 415, 655-659. [CrossRef]

20. Kuznetsova, A.A.A.; Fedorova, O.O.S.O.; Kuznetsov, N.N.A.N. Kinetic Features of $3^{\prime}-5^{\prime}$ Exonuclease Activity of Human AP-Endonuclease APE1. Molecules 2018, 23, 2101. [CrossRef]

21. Kerins, S.M.; Collins, R.; McCarthy, T.V. Characterization of an endonuclease IV $3^{\prime}-5^{\prime}$ exonuclease activity. J. Biol. Chem. 2003, 278, 3048-3054. [CrossRef]

22. Wilson III, D.M.; Barsky, D. The major human abasic endonuclease: Formation, consequences and repair of abasic lesions in DNA. Mutat. Res. 2001, 485, 283-307. [CrossRef]

23. Mol, C.D.; Kuo, C.F.; Thayer, M.M.; Cunningham, R.P.; Tainer, J.A. Structure and Function of the Multifunctional DNA-Repair Enzyme Exonuclease-III. Nature 1995, 374, 381-386. [CrossRef]

24. Hosfield, D.J.; Guan, Y.; Haas, B.J.; Cunningham, R.P.; Tainer, J.A. Structure of the DNA repair enzyme endonuclease IV and its DNA complex: Double-nucleotide flipping at abasic sites and three-metal-ion catalysis. Cell 1999, 98, 397-408. [CrossRef]

25. Mol, C.D.; Hosfield, D.J.; Tainer, J.A. Abasic site recognition by two apurinic/apyrimidinic endonuclease families in DNA base excision repair: The $3^{\prime}$ ends justify the means. Mutat. Res. 2000, 460, 211-229. [CrossRef]

26. Garcin, E.D.; Hosfield, D.J.; Desai, S.A.; Haas, B.J.; Bjoras, M.; Cunningham, R.P.; Tainer, J.A. DNA apurinic-apyrimidinic site binding and excision by endonuclease IV. Nat. Struct. Mol. Biol. 2008, 15, 515-522. [CrossRef]

27. Mol, C.D.; Izumi, T.; Mitra, S.; Tainer, J.A. DNA-bound structures and mutants reveal abasic DNA binding by APE1 and DNA repair coordination. Nature 2000, 403, 451-456. [CrossRef] 
28. Tsutakawa, S.E.; Shin, D.S.; Mol, C.D.; Izumi, T.; Arvai, A.S.; Mantha, A.K.; Szczesny, B.; Ivanov, I.N.; Hosfield, D.J.; Maiti, B.; et al. Conserved structural chemistry for incision activity in structurally non-homologous apurinic/apyrimidinic endonuclease APE1 and endonuclease IV DNA repair enzymes. J. Biol. Chem. 2013, 288, 8445-8455. [CrossRef]

29. Miroshnikova, A.D.; Kuznetsova, A.A.; Vorobjev, Y.N.; Kuznetsov, N.A.; Fedorova, O.S. Effects of mono- and divalent metal ions on DNA binding and catalysis of human apurinic/apyrimidinic endonuclease 1. Mol. BioSyst. 2016, 12, 1527-1539. [CrossRef]

30. Kanazhevskaya, L.Y.; Koval, V.V.; Zharkov, D.O.; Strauss, P.R.; Fedorova, O.S. Conformational transitions in human AP endonuclease 1 and its active site mutant during abasic site repair. Biochemistry 2010, 49, 6451-6461. [CrossRef]

31. Timofeyeva, N.A.; Koval, V.V.; Knorre, D.G.; Zharkov, D.O.; Saparbaev, M.K.; Ishchenko, A.A.; Fedorova, O.S. Conformational dynamics of human AP endonuclease in base excision and nucleotide incision repair pathways. J. Biomol. Struct. Dyn. 2009, 26, 637-652. [CrossRef]

32. Miroshnikova, A.D.; Kuznetsova, A.A.; Kuznetsov, N.A.; Fedorova, O.S. Thermodynamics of Damaged DNA Binding and Catalysis by Human AP Endonuclease 1. Acta Nat. 2016, 8, 103-110. [CrossRef]

33. Zang, H.; Fang, Q.; Pegg, A.E.; Guengerich, F.P. Kinetic analysis of steps in the repair of damaged DNA by human O6alkylguanine-DNA alkyltransferase. J. Biol. Chem. 2005, 280, 30873-30881. [CrossRef]

34. Yang, K.; Stanley, R.J. The extent of DNA deformation in DNA photolyase-substrate complexes: A solution state fluorescence study. Photochem. Photobiol. 2008, 84, 741-749. [CrossRef]

35. Kuznetsov, N.A.; Vorobjev, Y.N.; Krasnoperov, L.N.; Fedorova, O.S. Thermodynamics of the multi-stage DNA lesion recognition and repair by formamidopyrimidine-DNA glycosylase using pyrrolocytosine fluorescence-stopped-flow pre-steady-state kinetics. Nucleic Acids Res. 2012, 40, 7384-7392. [CrossRef]

36. Kladova, O.A.; Kuznetsov, N.A.; Fedorova, O.S. Thermodynamics of the DNA repair process by endonuclease VIII. Acta Nat. 2019, 11, 29-37. [CrossRef]

37. Kladova, O.A.; Krasnoperov, L.N.; Kuznetsov, N.A.; Fedorova, O.S. Kinetics and thermodynamics of DNA processing by wild type DNA-glycosylase endo III and its catalytically inactive mutant forms. Genes 2018, 9, 190. [CrossRef]

38. Kuznetsova, A.A.; Kuznetsov, N.A.; Vorobjev, Y.N.; Barthes, N.P.F.; Michel, B.Y.; Burger, A.; Fedorova, O.S. New EnvironmentSensitive Multichannel DNA Fluorescent Label for Investigation of the Protein-DNA Interactions. PLoS ONE 2014, 9, e100007. [CrossRef]

39. Kuznetsova, A.A.; Kladova, O.A.; Barthes, N.P.F.; Michel, B.Y.; Burger, A.; Fedorova, O.S.; Kuznetsov, N.A. Comparative Analysis of Nucleotide Fluorescent Analogs for Registration of DNA Conformational Changes Induced by Interaction with Formamidopyrimidine-DNA Glycosylase Fpg. Russ. J. Bioorgan. Chem. 2019, 45. [CrossRef]

40. Kuznetsova, A.A.; Kuznetsov, N.A.; Ishchenko, A.A.; Saparbaev, M.K.; Fedorova, O.S. Pre-steady-state fluorescence analysis of damaged DNA transfer from human DNA glycosylases to AP endonuclease APE1. Biochim. Biophys. Acta 2014, $1840,3042-3051$. [CrossRef]

41. Harlow, E.; Lane, D. Bradford Assay. Cold Spring Harb. Protoc. 2006, 2006, 4644. [CrossRef]

42. Kuzmic, P. Program DYNAFIT for the analysis of enzyme kinetic data: Application to HIV proteinase. Anal. Biochem. 1996, 237, 260-273. [CrossRef]

43. Kuznetsov, N.A.; Koval, V.V.; Nevinsky, G.A.; Douglas, K.T.; Zharkov, D.O.; Fedorova, O.S. Kinetic conformational analysis of human 8-oxoguanine-DNA glycosylase. J. Biol. Chem. 2007, 282, 1029-1038. [CrossRef]

44. Alekseeva, I.V.; Bakman, A.S.; Vorobjev, Y.N.; Fedorova, O.S.; Kuznetsov, N.A. Role of Ionizing Amino Acid Residues in the Process of DNA Binding by Human AP Endonuclease 1 and in Its Catalysis. J. Phys. Chem. 2019, 123, 9546-9556. [CrossRef]

45. Yakovlev, D.A.; Kuznetsova, A.A.; Fedorova, O.S.; Kuznetsov, N.A. Search for Modified DNA Sites with the Human Methyl-CpGBinding Enzyme MBD4. Acta Nat. 2017, 9, 88-98. [CrossRef]

46. Alekseeva, I.V.; Kuznetsova, A.A.; Bakman, A.S.; Fedorova, O.S.; Kuznetsov, N.A. The role of active-site amino acid residues in the cleavage of DNA and RNA substrates by human apurinic/apyrimidinic endonuclease APE1. Biochim. Biophys. Acta (BBA) Gen. Subj. 2020, 1864, 129718. [CrossRef]

47. Kladova, O.A.; Kuznetsova, A.A.; Fedorova, O.S.; Kuznetsov, N.A. Mutational and Kinetic Analysis of Lesion Recognition by Escherichia coli Endonuclease VIII. Genes 2017, 8, 140. [CrossRef] [PubMed]

48. Kuznetsov, N.A.; Fedorova, O.S. Kinetic milestones of damage recognition by DNA glycosylases of the Helix-hairpin-Helix structural superfamily. Adv. Exp. Biol. Med. 2020, 1241, 1-18.

49. Kuznetsova, A.A.; Matveeva, A.G.; Milov, A.D.; Vorobjev, Y.N.; Dzuba, S.A.; Fedorova, O.S.; Kuznetsov, N.A. Substrate specificity of human apurinic/apyrimidinic endonuclease APE1 in the nucleotide incision repair pathway. Nucleic Acids Res. 2018, 46, 11454-11465. [CrossRef]

50. Hegde, M.L.; Hazra, T.K.; Mitra, S. Functions of disordered regions in mammalian early base excision repair proteins. Cell. Mol. Life Sci. 2010, 67, 3573. [CrossRef]

51. Antoniali, G.; Lirussi, L.; Poletto, M.; Tell, G. Emerging roles of the nucleolus in regulating the DNA damage response: The noncanonical DNA repair enzyme APE1/Ref-1 as a paradigmatical example. Antioxid. Redox Signal. 2014, 20, 621-639. [CrossRef]

52. Davletgildeeva, A.T.; Ishchenko, A.A.; Saparbaev, M.; Fedorova, O.S.; Kuznetsov, N.A. The Enigma of Substrate Recognition and Catalytic Efficiency of APE1-Like Enzymes. Front. Cell Dev. Biol. 2021, 9, 532. [CrossRef] [PubMed] 
53. Fantini, D.; Vascotto, C.; Marasco, D.; D’Ambrosio, C.; Romanello, M.; Vitagliano, L.; Pedone, C.; Poletto, M.; Cesaratto, L.; Quadrifoglio, F.; et al. Critical lysine residues within the overlooked N-terminal domain of human APE1 regulate its biological functions. Nucleic Acids Res. 2010, 38, 8239-8256. [CrossRef]

54. Poletto, M.; Vascotto, C.; Scognamiglio, P.L.; Lirussi, L.; Marascod, D.; Tell, G. Role of the unstructured N-terminal domain of the hAPE1 (human apurinic/apyrimidinic endonuclease 1) in the modulation of its interaction with nucleic acids and NPM1 (nucleophosmin). Biochem. J. 2013, 452, 545-557. [CrossRef] [PubMed]

55. Chattopadhyay, R.; Wiederhold, L.; Szczesny, B.; Boldogh, I.; Hazra, T.K.; Izumi, T.; Mitra, S. Identification and characterization of mitochondrial abasic (AP)-endonuclease in mammalian cells. Nucleic Acids Res. 2006, 34, 2067-2076. [CrossRef]

56. Izumi, T.; Mitra, S. Deletion analysis of human AP-endonuclease: Minimum sequence required for the endonuclease activity. Carcinogenesis 1998, 19, 525-527. [CrossRef] [PubMed]

57. Kladova, O.A.; Bazlekowa-Karaban, M.; Baconnais, S.; Piétrement, O.; Ishchenko, A.A.; Matkarimov, B.T.; Iakovlev, D.A.; Vasenko, A.; Fedorova, O.S.; Le Cam, E.; et al. The role of the N-terminal domain of human apurinic/apyrimidinic endonuclease 1, APE1, in DNA glycosylase stimulation. DNA Repair 2018, 64, 10-25. [CrossRef]

58. Moor, N.; Vasil'eva, I.; Lavrik, O. Functional role of N-terminal extension of human ap endonuclease 1 in coordination of base excision dna repair via protein-protein interactions. Int. J. Mol. Sci. 2020, 21, 3122. [CrossRef]

59. Popov, A.V.; Grin, I.R.; Dvornikova, A.P.; Matkarimov, B.T.; Groisman, R.; Saparbaev, M.; Zharkov, D.O. Reading Targeted DNA Damage in the Active Demethylation Pathway: Role of Accessory Domains of Eukaryotic AP Endonucleases and Thymine-DNA Glycosylases. J. Mol. Biol. 2020, 432, 1747-1768. [CrossRef]

60. López, D.J.; Rodríguez, J.A.; Bañuelos, S. Molecular Mechanisms Regulating the DNA Repair Protein APE1: A Focus on Its Flexible N-Terminal Tail Domain. Int. J. Mol. Sci. 2021, 22, 6308. [CrossRef] [PubMed]

61. Bazlekowa-Karaban, M.; Prorok, P.; Baconnais, S.; Taipakova, S.; Akishev, Z.; Zembrzuska, D.; Popov, A.V.; Endutkin, A.V.; Groisman, R.; Ishchenko, A.A.; et al. Mechanism of stimulation of DNA binding of the transcription factors by human apurinic/apyrimidinic endonuclease 1, APE1. DNA Repair 2019, 82, 102698. [CrossRef]

62. Kelley, M.R.; Georgiadis, M.M.; Fishel, M.L. APE1/Ref-1Role in Redox Signaling: Translational Applications of Targeting the Redox Function of the DNA Repair/Redox Protein APE1/Ref-1. Curr. Mol. Pharmacol. 2011, 5, 36-53. [CrossRef] [PubMed]

63. Georgiadis, M.M.; Luo, M.; Gaur, R.K.; Delaplane, S.; Li, X.; Kelley, M.R. Evolution of the redox function in mammalian apurinic/apyrimidinic endonuclease. Mutat. Res. Fundam. Mol. Mech. Mutagen. 2008, 643, 54-63. [CrossRef] [PubMed]

64. Vascotto, C.; Fantini, D.; Romanello, M.; Cesaratto, L.; Deganuto, M.; Leonardi, A.; Radicella, J.P.; Kelley, M.R.; D’Ambrosio, C.; Scaloni, A.; et al. APE1/Ref-1 Interacts with NPM1 within Nucleoli and Plays a Role in the rRNA Quality Control Process. Mol. Cell. Biol. 2009, 29, 1834-1854. [CrossRef]

65. Tell, G.; Wilson, D.M.; Lee, C.H. Intrusion of a DNA Repair Protein in the RNome World: Is This the Beginning of a New Era? Mol. Cell. Biol. 2010, 30, 366-371. [CrossRef] [PubMed]

66. Antoniali, G.; Serra, F.; Lirussi, L.; Tanaka, M.; D’Ambrosio, C.; Zhang, S.; Radovic, S.; Dalla, E.; Ciani, Y.; Scaloni, A.; et al. Mammalian APE1 controls miRNA processing and its interactome is linked to cancer RNA metabolism. Nat. Commun. 2017, 8, 797. [CrossRef]

67. Takeuchi, M.; Lillis, R.; Demple, B.; Takeshita, M. Interactions of Escherichia coli Endonuclease IV and Exonuclease III with Abasic Sites in DNA. J. Biol. Chem. 1994, 269, 21907-21914. [CrossRef] 